\title{
Pengembangan E-Modul Interaktif Berbasis Android pada Mata Kuliah Strategi Belajar Mengajar
}

\author{
Ricu Sidiq, Najuah \\ Jurusan Pendidikan Sejarah, Universitas Negeri Medan \\ Email : ricusidiq@unimed.ac.id
}

\begin{abstract}
This research aims to develop an interactive e-module for Android based on the Teaching and Learning Strategy Course. The subject of this research were students of History Education Department 2017, State University of Medan. The method used in this research was $R \mathcal{E D}$. Using the Borg and Gall development model which included the first steps; Preliminary research (preparation, deepening survey, need analysis), second; Product development Planning (data collecting, product identification development), third; Product validation and revision (expert study, small group trials, large group trials), fourth; Product implementation (planning, preparation, implementation, observation, evaluation). This development research resulted in a product that meets the validation by material experts reaching $93 \%$ with a highly valid category, learning design experts reach $82 \%$ by valid categories, media experts reach $86 \%$ with valid categories and $86 \%$ for effectiveness media usage. The implications of the results of this research is that it can improve, trigger, strengthen students interest to study independently and the process of learning more effective, efficiency so that can improve the learning quality.
\end{abstract}

Keywords : Android, Interactive E-Module, Teaching and Learning Strategy, $R \in \mathcal{D}$

\begin{abstract}
Abstrak: Penelitian ini bertujuan untuk mengembangkan e-modul interaktif berbasis Android pada mata kuliah Strategi Belajar Mengajar. Subjek penelitian ini angkatan 2017 jurusan pendidikan sejarah unimed. Metode yang digunakan dalam penelitian ini adalah $R \mathcal{E}$. dengan menggunakan model pengembangan Borg and Gall yang meliputi langkah-langkah pertama; penelitian pendahuluan (persiapan, survey pendalaman, analisis kebutuhan), kedua; perencanaan pengembangan produk (pengumpulan data, identifikasi produk yang dikembangkan), ketiga; validasi dan revisi produk (telaah pakar, uji coba kelompok kecil, uji coba kelompok besar), keempat; implementasi produk (perencanaan, persiapan, pelaksanaan, observasi, evaluasi). Penelitian pengembangan ini menghasilkan produk yang memenuhi validasi oleh ahli materi mencapai $93 \%$ dengan kategori sangat valid, ahli desain pembelajaran mencapai $82 \%$ dengan kategori valid, ahli media mencapai $86 \%$ dengan kategori valid dan $86 \%$ persentase untuk efektifitas penggunaan media. Implikasi dari hasil penelitian ini adalah dapat membangun, memicu, memperkuat minat mahasiswa untuk belajar secara mandiri dan proses pembelajaran lebih efektivitas, efesiensi sehingga terjadi peningkatan kualitas pembelajaran.
\end{abstract}

Kata kunci: Android, E-Modul Interaktif, SBM, $R \& D$. 


\section{PENDAHULUAN}

Arus globalisasi kian semakin tidak terbendung tak terkecuali di Indonesia. Globalisasi yang juga disertai dengan perkembangan teknologi yang semakin canggih, membuktikan bahwa dunia sudah memasuki era revolusi industri 4.0. Era ini menekankan pada pola digital economy, artificial intelligence, big data, robotic, dan lain sebagainya atau biasa yang dikenal dengan fenomena disruptive innovation. Menghadapi fenomena ini, pengajaran di perguruan tinggi pun dituntut untuk berubah termasuk dalam menghasilkan dosen yang berkualitas yang dapat menghasilkan lulusan yang dapat menjawab tantangan era disrupsi. Menanggapi hal demikian, Rektor UNIMED, Syawal Gultom mengarahkan agar para dosen harus melakukan pengembangan bahan perkuliahan dengan mengintegrasikan konten baru ke dalam bahan perkuliahan dan menghilangkan bahan perkuliahan yang out of date juga harus melakukan tes standar pada mata kuliah agar dapat menciptakan lulusan yang high skill, membangun nalar sehat dan produktif.

Peningkatan kualitas pembelajaran di perguruan tinggi harus sejalan dengan perkembangan teknologi komunikasi dan informasi yang sedang berkembang luas di masyarakat. Berbagai strategi dan salah satu alternatif yang dapat dilakukan adalah dengan melakukan pengembangan bahan ajar. Dimana pengembangan bahan ajar dilakukan oleh seorang dosen untuk memecahkan permasalahan pembelajaran dengan memperhatikan sasaran atau mahasiswa dan juga menyesuaikan dengan kompetensi yang harus dicapai. Salah satu bentuk bahan ajar yang dapat dikembangkan adalah modul. 
Hingga saat ini, buku teks masih merupakan salah satu produk utama yang belum tergantikan, termasuk dalam pembelajaran. Sayangnya terdapat kelemahan pada buku teks, yaitu : tidak mampu memvisualisasikan peristiwa/fenomena secara dinamis, kurang interaktif, dan tidak mendukung belajar multi sumber. Selain itu, meskipun mahasiswa memiliki buku cetak, akan tetapi mereka tetap saja sering lupa untuk membawanya. Dosen perlu menggunakan dan mengembangkan bahan ajar tambahan yang mampu melengkapi kekurangan yang dimiliki buku teks yaitu dengan pengembangan modul.

Saat ini, sebagaian besar modul dibuat dalam bentuk cetak. Modul dalam bentuk ini cenderung monoton dan kurang dapat diminati mahasiswa. Salah satu cara agar modul dapat lebih diminati mahasiswa adalah dengan menciptakan modul dalam bentuk elektronik yang dapat dijadikan suatu produk interaktif karena dapat disisipi produk lain seperti gambar, animasi, audio, maupun video, selain itu dengan perkembangan teknologi yang semakin pesat terutama mahasiswa sudah tidak asing lagi dengan penggunaan android. Oleh karena itu harus dapat dikembangkan modul elektronik (E-modul) interaktif untuk pembelajaran.

Pengembangan modul disini sejalan dengan tantangan di era disrupsi sehingga modul yang dikembangakan dan akan digunakan dalam proses pembelajaran tentulah modul yang sudah dikembangkan dengan menggunakan kemajuan teknologi komunikasi dan informasi yang sedang berkembang di masyarakat dengan memanfaatkan internet serta kecanggihan android.

Produk dari teknologi dan infomasi telah memberikan alternatif bahan ajar yang dapat digunakan dan diakses mahasiswa dalam bentuk 
digital seperti e-modul. Berdasarkan penelitian Herawati dan Muhtadi (2018), modul elektronik merupakan modul yang efektif mempengaruhi hasil berlajar siswa. Pembelajaran interaktif berbasis android mampu mengaktifkan mahasiswa untuk belajar dengan motivasi yang tinggi karena ketertarikannya pada sistem multiproduk. E-modul interaktif berbasis android merupakan modul yang produk yang dianggap cukup ideal sekarang ini. Karena mendukung penggunaan multiproduk (keterpaduan audio-visual berbentuk video), interaktifitas yang tinggi, dan pembelajaran multi sumber (dengan koneksi jaringan internet) sehingga dapat melengkapi kekurangan-kekurangan yang ada pada buku teks.

.E-module secara etimologis terdiri dari dua kata, yakni singkatan " $\mathrm{e}$ " atau "electronic" dan "module". Simarmata (2017 : 96) menyebut bahwa modul adalah satuan kegiatan belajar terencana yang didesain guna membantu siswa menyelesaikan tujuan-tujuan tertentu dengan cara pengorganisasian materi pelajaran yang disesuaikan dengan pribadi individu itu sendiri sehingga dapat memaksimalkan kemampuan intelektualnya. Modul dirancang secara khusus dan jelas berdasarkan kecepatan pemahaman masing-masing siswa, sehingga mendorong siswa untuk belajar sesuai dengan kemampuanya. Seiring dengan perkembangan IPTEK saat ini mulai terjadi transisi dari media cetak menjadi media digital. Modul pembelajaran juga mengalami transformasi dalam hal penyajiannya ke bentuk elektronik, yang dikenal sebagai modul elektronik (e-module).

Modul elektronik adalah sumber belajar yang berisi materi, metode, batasan-batasan dan cara meng-evaluasi yang dirancang sistematis dan 
menarik untuk mencapai kompetensi yang sesuai kurikulum secara elektronik (Laili, dkk. 2019 : 309). Selanjutnya, Samiasih (2017 : 119) mendefinisikan E-module merupakan modul yang berbasis komputer dan berisi penggalan-penggalan dengan pertanyaan di setiap penggalan agar membuat pengguna lebih mudah memahami materi. Untuk mengurangi kejenuhan mahasiswa belajar dengan modul, bahan ajar digital dalam bentuk modul elektronik ini dapat dikembangkan menjadi media pembelajaran interaktif atau yang dikenal sebagai e-modul interaktif.

E-modul interaktif merupakan bahan pembelajaran yang berisi materi, metode, batasan-batasan dan cara mengevaluasi yang dirancang secara sistematis dan menarik untuk mencapai kompetensi/subkompetensi mata kuliah yang diharapkan sesuai dengan tingkat kompleksitasnya, Imansari dan Suryatiningsih (2017:12). Dikatakan interaktif karena pengguna akan mengalami interaksi dan bersikap aktif misal aktif memperhatikan gambar, memperhatikan tulisan yang bervariasi warna atau bergerak, suara, animasi bahkan video dan film. Kondisi interaktif akan meningkatkan nilai komunikasi yang snagat tinggi, artinya innformasi tidak hanya dapat dilihat sebagai cetakan, melainkan juga dapat didengar, serta membentuk simulasi dan animasi yang dapat membangkitkan semangat dan memiliki nilai grafis yang tinggi dalam penyajiannya. Hal itu sesuai dengan pendapat Kurniawan (2015) modul interaktif dapat didefinisikan sebagai sebuah multimedia yang berupa kombinasi dua atau lebih media (audio, teks, grafik, gambar, animasi dan video) yang disajikan dalam bentuk compact disk (CD) dan terjadi interaksi (hubungan timbal balik/komunikasi dua arah atau lebih) antara media dan penggunanya. 
lstiyanto (2013) menyebutkan bahwa android merupakan suatu sistem software stack yang terhubung dan terdistribusi secara open source (terbuka) yang terdiri dari sistem operasi, middleware, dan aplikasi dasar (key application). Referensi lain dari Satyaputra dan aritonang (2014) menyebutkan bahwa android adalah sebuah sistem operasi untuk smartphone dan tablet. Sistem operasi dapat diilustrasikan sebagai jembatan antara piranti (device) dan penggunanya sehingga pengguna dapat bernteraksi dengan device-nya dan menjalankan aplikasi-alikasi yang tersedia pada device. Andry (2011) mengatakan sistem operasi android merupakan modifikasi dari kenel Linux. Linux yang mempunyai sifat open source (terbuka) sehingga programer dapat mengembangkan aplikasi android maupun memodifikasi sistem.

Android merupakan sistem operasi yang sangat populer digunakan dibandingkan sistem lainnya. Hal ini dikarenakan sifat yang dimiliki android, yakni Lengkap, Terbka dan Free. Sifat android yang lengkap (complete platform) memungkinkan para pembuat software bebas membuat pendekatan dalam mengembangkan software, androi juga sistem operasi yang aman dan banyak tersedia peralatan untuk membangun software. Android disedikan secara terbuka (open source) sehingga pengembang dengan bebas mengembangkan aplikasi. Sifat android free platform memudahkan pengguna dengan bebas membuat aplikasi tanpa royalti yang harus dibayarkan, tidak ada keanggotaan, tidak ada biaya pengujian, tidak ada kontrak yang iperlukan dan dapat didistribusikan secara bebas dalam berbagai bentuk, Safaat (2012).

Menanggapi arahan dari Rektor Unimed dan melihat kebutuhan mencetak calon guru serta tuntutan perkembangan zaman revolusi 
industri 4.0, penulis bermaksud untuk mengembangkan E-modul interaktif berbasis android untuk Mata Kuliah strategi Belajar Mengajar (SBM) di angkatan 2017 jurusan pendidikan sejarah.

\section{METODE}

Metode yang digunakan dalam penelitian ini adalah $R \mathcal{E} D$. Dengan menggunakan model pengembangan Borg and Gall yang meliputi langkah-langkah pertama; penelitian pendahuluan (persiapan, survey pendalaman, analisis kebutuhan), kedua; perencanaan pengembangan produk (pengumpulan data, identifikasi produk yang dikembangkan), ketiga; validasi dan revisi produk (telaah pakar, uji coba kelompok kecil, uji coba kelompok besar), keempat; implementasi produk (perencanaan, persiapan, pelaksanaan, observasi, evaluasi). Penelitian ini menjelaskan bagaimana mendisain pengembangan program E-Modul Interaktif berbasis Android, sehingga terjadi peningkatan efektivitas dan efesiensi pembelajaran matakuliah Starategi Belajar Mengajar.

\section{HASIL DAN PEMBAHASAN}

\section{Data Hasil Validasi Ahli Materi}

Validasi ahli materi pada media pembelajaran berbasis android yang dikembangkan oleh satu ahli materi yaitu Dr. Samsidar Tanjung, M.Pd yang merupakan dosen Jurusan Pendidikan Sejarah Universitas Negeri Medan. Penilaian dilakukan untuk meningkatkan kualitas isi materi dari E-modul interaktif berbasis android untuk mahasiswa angkatan 2017 pada semester ganjil. Hasil validasi terhadap komponen-komponen pada kualitas materi media pembelajaran E-modul interaktif berbasis android dapat dilihat pada gambar 1 berikut : 


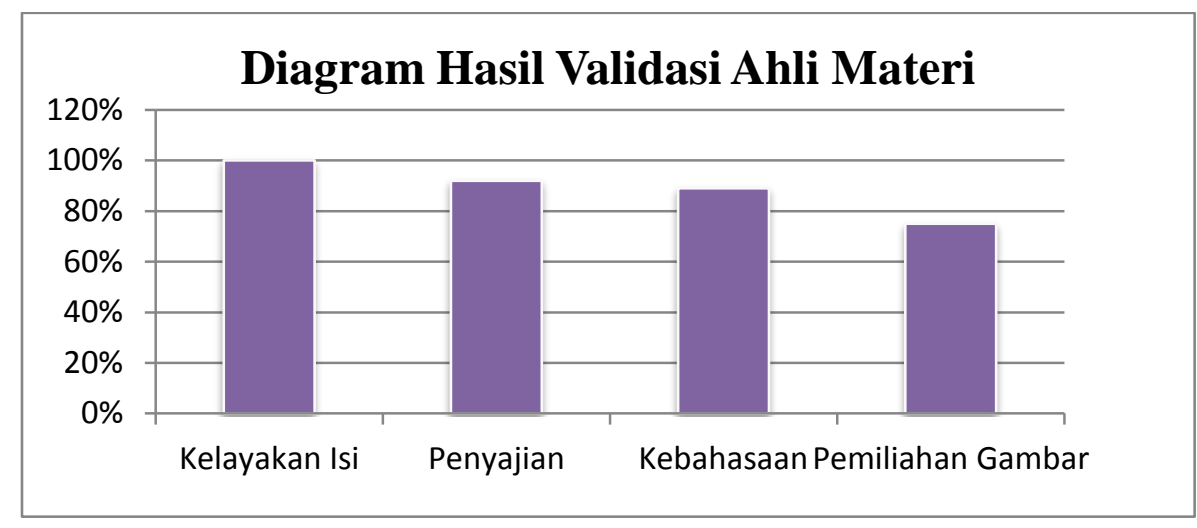

Gambar 1. Hasil Validasi Ahli Materi

Berdasarkan data hasil validasi ahli materi diatas dapat dilihat bahwa kelayakan isi, penyajian, kebahasaan, dan pemilihan gambar pada E-modul interaktif berbasis android secara umum masuk dalam kategori "Sangat Valid" dengan persentase 93\%.

\section{Data Hasil Validasi Ahli Desain Pembelajaran}

Validasi desain pembelajaran pada media pembelajaran berbasis android yang dikembangkan dilakukan oleh ahli yaitu Eko Ribawati, S.Pd.,M.Pd. yang merupakan dosen jurusan pendidikan sejarah di Universitas Agengtirtayasa. Hasil validasi media pembelajaran berupa skor penilaian yang berkaitan dengan bidang desain pembelajaran diantaranya pendekatan pembelajaran, kebenaran konsep, kedalaman konsep, kesesuaian konsep, kegiatan pembelajaran, kegiatan percobaan, keterlaksanaan, penilaian, isi, visualisasi, dan kejelasan kalimat yang termasuk kualitas tampilan media pembelajaran yang dapat dilihat pada gambar 2 berikut : 


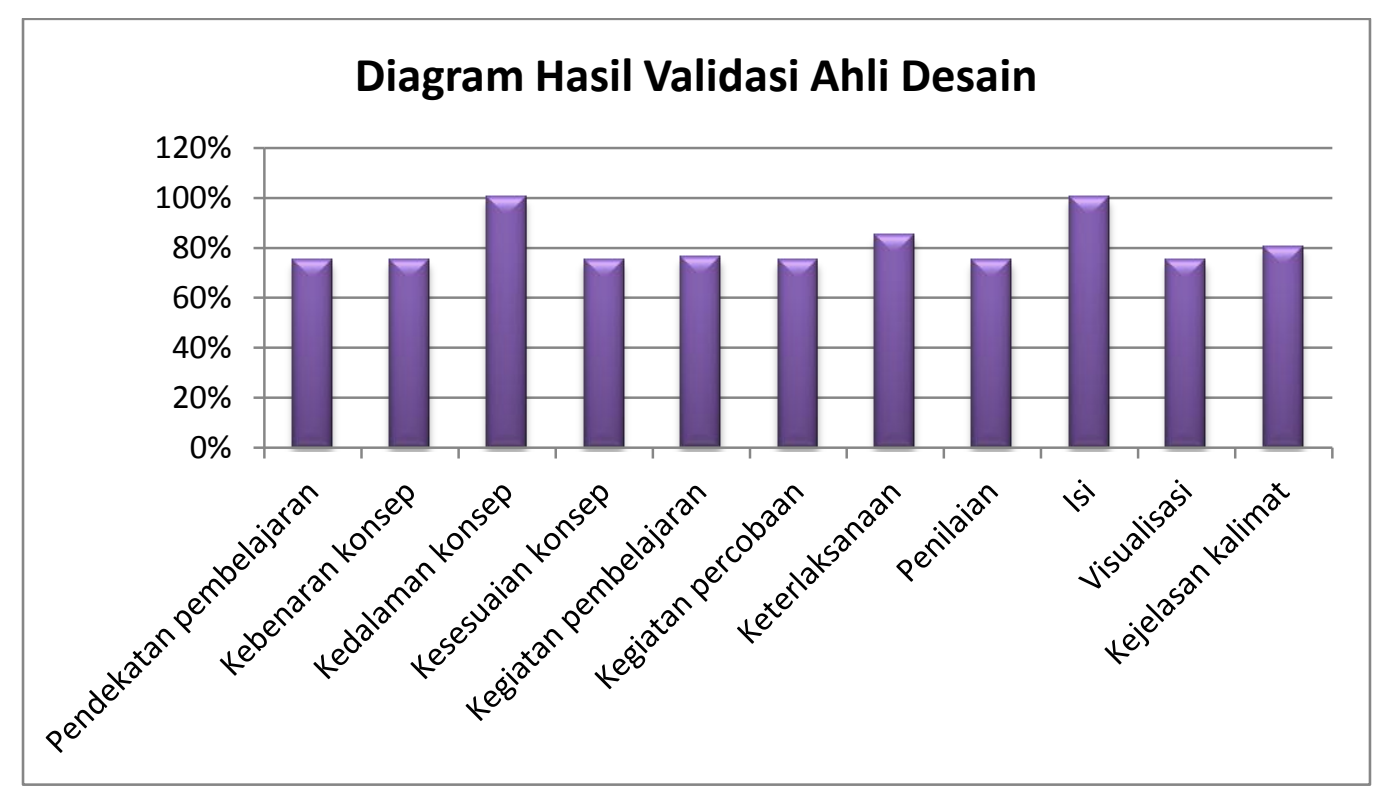

Gambar 2. Hasil Validasi Ahli Desain Pembelajaran

Berdasarkan data hasil validasi ahli desain pembelajaran sesuai pada tabel diatas dapat dilihat bahwa pendekatan pembelajaran, kebenaran konsep, kedalaman konsep, kesesuaian konsep, kegiatan pembelajaran, kegiatan percobaan, keterlaksanaan, penilaian, isi, visualisasi, dan kejelasan kalimat secara umum dalam kategori "Valid" dengan persentase $82 \%$.

\section{Data Hasil Validasi Media}

Validasi media pada media pembelajaran berbasis android yang dikembangkan dilakukan oleh ahli yaitu Lukita Fajri, S.s yang merupakan ketua rumah coding. Pada proses validasi dilakukan terkait desain layout/tata letak, teks/typografi, image, kemasan. Penggunaan, navigasi, dan interactive link. Adapun hasil validasi pada kualitas media dari E- Modul interaktif berbasis android dapat dilihat pada gambar 3 sebagai berikut: 


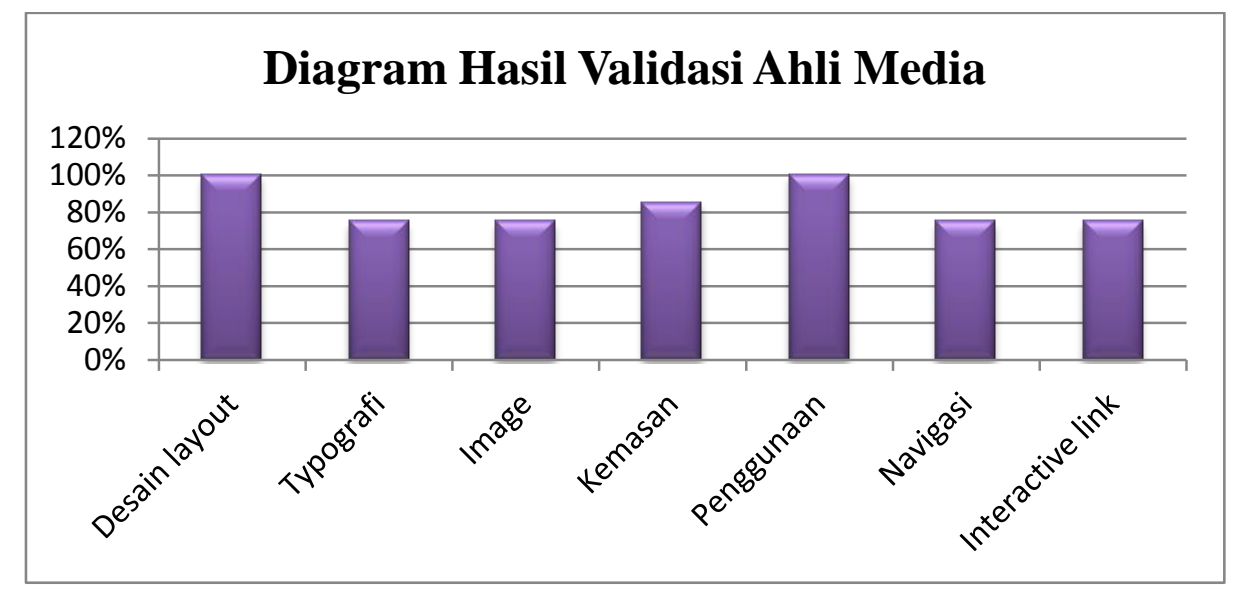

Gambar 3. Hasil Validasi oleh Ahli Media

Berdasarkan data hasil validasi ahli media sesuai pada tabel diatas dapat dilihat bahwa tampilan desain layout/tata letak, teks/typografi, image, kemasan, navigasi, dan interactive link secara umum dalam kategori "Valid" dengen persentase $86 \%$.

\section{Uji Coba Kecil}

Uji coba kecil dilakukan di jurusan pendidikan sejarah. Uji coba kecil dilakukan pada 3 orang, yaitu mahasiswa dari kelas C. Tujuan dari uji coba kecil ini dilakukan untuk mengidentifikasi kekurangan produk dan persepsi terhadap e-modul interaktif berbasis Android yang telah dikembangkan setelah divalidasi oleh tim ahli. Setelah dilakukan uji coba kecil, maka peneliti melakukan revisi e-modul interaktif berbasis android berdasarkan masukan yang telah diberikan. Hasil penilaian mahasiswa terhadap e-modul interaktif berbasis android yang telah dikembangkan dapat dilihat pada tabel 1 berikut :

Tabel 1. Hasil Persentase Kelayakan pada Uji Coba Kecil

\begin{tabular}{lccc}
\hline \multicolumn{1}{c}{ Nama } & Skor Total & Skor Maksimal & Persentase \\
\hline Adinda Novianti & 50 & 80 & $63 \%$ \\
Melati Safitri & 51 & 80 & $64 \%$ \\
Rahmadi Wikan & 50 & 80 & $63 \%$ \\
\hline \multicolumn{1}{c}{ Total } & $\mathbf{1 5 1}$ & $\mathbf{2 4 0}$ & \\
\hline Persentase total & & & $\mathbf{6 3 \%}$ \\
$\quad$ Keterangan & & & Cukup layak \\
\hline
\end{tabular}


Persentase kelayakan terhadap e-modul interaktif berbasis android pada saat dilakukan uji coba kecil dapat dilihat pada tabel 5.8 diatas bahwa media di kategorikan "Cukup layak" dengan persentase 63\%.

\section{Uji Coba Sedang}

Penilaian dilakukan oleh 10 orang mahasiswa kelas A dengan tujuan untuk mengetahui respon mahasiswa terhadap kelayakan e-modul interaktif berbasis android yang dikembangkan. Hasil respon mahasiswa pada saat uji coba sedang terhadap e-modul interaktif berbasis android yang telah dikembangkan dapat dilihat pada tabel 2 berikut :

Tabel 2. Hasil Persentase Kelayakan Media pada Uji Coba Sedang

\begin{tabular}{|c|c|c|c|}
\hline Nama & $\begin{array}{l}\text { Skor } \\
\text { Total } \\
\end{array}$ & Skor Maksimal & Persentase \\
\hline Ester Kristina BR Manurung & 52 & 80 & $65 \%$ \\
\hline Imanuel Ambarita & 59 & 80 & $74 \%$ \\
\hline Khosim Hasibuan & 55 & 80 & $69 \%$ \\
\hline Mita Novi Dila & 48 & 80 & $60 \%$ \\
\hline Nilwan Perangin-angin & 53 & 80 & $66 \%$ \\
\hline Riski Lazuardi & 57 & 80 & $71 \%$ \\
\hline Riska Wati Siahaan & 53 & 80 & $66 \%$ \\
\hline Sefia F Habeahan & 56 & 80 & $70 \%$ \\
\hline Indah Khairani & 50 & 80 & $63 \%$ \\
\hline Rahimah & 48 & 80 & $60 \%$ \\
\hline Total & 531 & 800 & \\
\hline Persentase total & & & $66 \%$ \\
\hline Keterangan & & & Cukup layak \\
\hline
\end{tabular}

Persentase kelayakan terhadap e-modul interaktif berbasis android pada saat melakukan uji coba sedang dapat dilihat pada tabel 2 dikategorikan "Cukup layak" dengan persentase 66\%.

\section{Uji Coba Besar}

Uji coba besar dilakukan dikelas B dengan jumlah mahasiswa 24 orang. Hasil respon mahasiswa pada saat uji coba sedang terhadap e- 
modul interaktif berbasis android yang telah dikembangkan dapat dilihat pada tabel 3 berikut :

Tabel 3. Hasil Persentase Kelayakan pada Uji Coba Besar

\begin{tabular}{lccc}
\hline \multicolumn{1}{c}{ Nama } & Skor Total & Skor Maksimal & Persentase \\
\hline Esra Satria H Lumbangaol & 52 & 80 & $65 \%$ \\
Niken Pratiwi Lubis & 52 & 80 & $65 \%$ \\
Ningsih Maria.PR.P & 58 & 80 & $73 \%$ \\
Nur Hidayah & 46 & 80 & $58 \%$ \\
Santonius Silaban & 52 & 80 & $65 \%$ \\
Zimmi Idaman Sitepu & 49 & 80 & $61 \%$ \\
Anan Bakri Lubis & 55 & 80 & $69 \%$ \\
Bersama Indah Rejeki S Pane & 52 & 80 & $65 \%$ \\
Ratih Andriani & 51 & 80 & $64 \%$ \\
Hafiz Rizaldi & 46 & 80 & $58 \%$ \\
Nur Aisyah & 45 & 80 & $56 \%$ \\
Sasya Sarens & 48 & 80 & $60 \%$ \\
Ferdina Waty Lase & 48 & 80 & $60 \%$ \\
Frenki Ramli Marbun & 48 & 80 & $60 \%$ \\
Marlina BR Tarigan & 48 & 80 & $60 \%$ \\
Nopita Rosana Sihombing & 51 & 80 & $64 \%$ \\
Yeremia Somura Pasaribu & 51 & 80 & $64 \%$ \\
Yoshe Refael Hutasoit & 57 & 80 & $71 \%$ \\
Angitha Agusti BR Ginting & 53 & 80 & $66 \%$ \\
Anisah Almadani Pangat & 56 & 80 & $70 \%$ \\
Aulia Rizki Pramata & 52 & 80 & $65 \%$ \\
Della BR Ginting & 51 & 80 & $64 \%$ \\
Indah Juliani & 47 & 80 & $59 \%$ \\
Rahmad Ashari & 48 & $\mathbf{1 9 2 0}$ & $60 \%$ \\
\hline \multicolumn{1}{c}{ Total } & $\mathbf{1 2 1 6}$ & & \\
\hline \multicolumn{1}{c}{ Persentase total } & & & $\mathbf{6 u k} \%$ \\
\hline Keterangan & & & \\
\hline
\end{tabular}

Persentase kelayakan terhadap e-modul interaktif berbasis android pada saat melakukan uji coba besar dapat dilihat pada tabel 5.10 diatas bahwa media dikategorikan "Cukup layak" dengan persentase 63\%. 


\section{Hasil Pembelajaran}

Tabel 7. Rangkuman Nilai Rata-rata Pretest dan Posttest

\begin{tabular}{cccc}
\hline Sumber Data & $\begin{array}{c}\text { Nilai Rata-rata } \\
\text { pretest }\end{array}$ & $\begin{array}{c}\text { Nilai Rata-rata } \\
\text { Posttest }\end{array}$ & Selisih \\
\hline Mahasiswa Kelas A (30 orang) & 61 & 86 & 25 \\
\hline
\end{tabular}

Berdasarkan tabel diatas dapat disimpulkan bahwa pembelajaran matakuliah strategi belajar mengajar sejarah menggunakan e-modul interaktif berbasis Android dapat meningkatkan hasil belajar mahasiswa.

\section{KESIMPULAN}

E-modul interaktif berbasis Android yang dikembangkan ini telah divalidasi dan memenuhi kriteria media pembelajaran yang baik dan layak untuk digunakan dalam pembelajaran matakuliah strategi belajar mengajar sejarah di jurusan pendidikan sejarah, dimana 93\% validasi oleh ahli materi, $82 \%$ validasi oleh ahli desain pembelajaran, dan $86 \%$ validasi oleh ahli media. Sedangkan kelayakan dari uji coba masing-masing berkisar $63 \%$ untuk uji coba kecil, 66\% untuk uji coba sedang, dan $63 \%$ untuk uji coba besar.

E-modul interaktif berbasis Android yang dikembangkan sudah efektif digunakan untuk meningkatkan hasil belajar mahasiswa dalam proses pembelajaran. Hal ini dapat dilihat dari analisis hasil belajar mahasiswa dengan menggunakan media pembelajaran berbasis Android lebih efisien, dimana diperoleh nilai posttest lebih besar dibanding pretest. 


\section{DAFTAR PUSTAKA}

[1] Andry. (2011). Android A sampai Z. Jakarta: Rineka Cipta.

[2] Herawati, Nita Sunarya., Muhtadi, Ali. (2018). Pengembangan Modul Elektronik (E-Modul) Interakif pada Mata Pelajaran Kimia Kelas XI SMA. Jurnal Inovasi Teknologi Pendidikan, 5(2) : 180 - 191.

[3] Imansari, N., Suryanintinningsih, Ina. (2017). Pengaruh Penggunaan E-Modul Interaktif terhadap Hasil Belajar Mahasiswa pada Materi Kesehatan dan Keselamatan Kerja. Jurnal Ilmiah Pendidikan Teknik Elektro, 2 (1): 11-16.

[4] Istiyanto, Eko Jazi. (2013). Pemograman Smartphone menggunakan SDK Android and Haking Android. Yogyakarta: Graha Ilmu

[5] Kurniawan, Deny., dkk. (2015). Pengembangan Modul Interaktif dengan Menggunakan Learning Content Development System pada Materi Listrik Dinamis. Jurnal Pembelajaran Fisika. 3 (6): 1-10.

[6] Laili, Ismail., Ganefri., Umeldi. (2019). Efektivitas Pengembangan EModul Project Based Learning pada Mata Pelajaran Instalasi Motor Listrik. Jurnal Ilmiah Pendidikan dan Pembelajaran, 3(3): 306-315.

[7] Safaat, Nazrudin. (2012). Pemograman Aplikasi Mobile Smartphone dan Tablet PC Berbasis Android. Bandung:Informatika.

[8] Samiasih, Reni., dkk. (2017). Pengembangan E-module mata pelajaran ilmu Pengetahuan alam pokok bahasan interaksi makhluk hidup dengan lingkungannya. Jurnal Edcomtech, 2(2): 119-124.

[9] Satyaputra dan Aritonang. (2014). Beginning Android Programiming with ADT Budle. Jakarta: Elex Media Komputindo.

[10] Simarmata, A.A., dkk. (2017). Pengembangan E-modul Berbasis Model Pembelajaran Project Based Learning pada Mata Pelajaran Pemrograman Desktop Kelas XI Rekayasa Perangkat Lunak di SMK Negeri 2 Tabanan. Jurnal KARMAPATI, 6(1): 93-102. 